\title{
Current perspectives: the impact of cyberbullying on adolescent health
}

This article was published in the following Dove Press journal:

Adolescent Health, Medicine and Therapeutics

I August 2014

Number of times this article has been viewed

\section{Charisse L Nixon \\ Pennsylvania State University, the Behrend College, Erie, PA, USA}

Correspondence: Charisse L Nixon 495I College Drive, Penn State University - Erie, Erie, PA, 16563 USA

Tel + I $8|4898604|$

$\mathrm{Fax}+18148986032$

Email cln5@psu.edu

\begin{abstract}
Cyberbullying has become an international public health concern among adolescents, and as such, it deserves further study. This paper reviews the current literature related to the effects of cyberbullying on adolescent health across multiple studies worldwide and provides directions for future research. A review of the evidence suggests that cyberbullying poses a threat to adolescents' health and well-being. A plethora of correlational studies have demonstrated a cogent relationship between adolescents' involvement in cyberbullying and negative health indices. Adolescents who are targeted via cyberbullying report increased depressive affect, anxiety, loneliness, suicidal behavior, and somatic symptoms. Perpetrators of cyberbullying are more likely to report increased substance use, aggression, and delinquent behaviors. Mediating/ moderating processes have been found to influence the relationship between cyberbullying and adolescent health. More longitudinal work is needed to increase our understanding of the effects of cyberbullying on adolescent health over time. Prevention and intervention efforts related to reducing cyberbullying and its associated harms are discussed.
\end{abstract}

Keywords: cyberbullying, adolescent health, prevention, intervention

\section{Current perspectives: the impact of cyberbullying on adolescent health}

Adolescents in the United States culture are moving from using the Internet as an "extra" in everyday communication (cyber utilization) to using it as a "primary and necessary" mode of communication (cyber immersion). ${ }^{1}$ In fact, $95 \%$ of adolescents are connected to the Internet. ${ }^{2}$ This shift from face-to-face communication to online communication has created a unique and potentially harmful dynamic for social relationships - a dynamic that has recently been explored in the literature as cyberbullying and Internet harassment.

In general, cyberbullying involves hurting someone else using information and communication technologies. This may include sending harassing messages (via text or Internet), posting disparaging comments on a social networking site, posting humiliating pictures, or threatening/intimidating someone electronically. ${ }^{3-7}$ Unfortunately, cyberbullying behavior has come to be accepted and expected among adolescents. ${ }^{8}$ Compared to traditional bullying, cyberbullying is unique in that it reaches an unlimited audience with increased exposure across time and space, ${ }^{6,9}$ preserves words and images in a more permanent state, ${ }^{10}$ and lacks supervision. ${ }^{6}$ Further, perpetrators of cyberbullying do not see the faces of their targets, ${ }^{11}$ and subsequently may not understand the full consequences of their actions, thereby decreasing important feelings of personal accountability. ${ }^{9}$ This has often been referred to in the literature as the "disinhibition effect". ${ }^{12}$ 
Cyberbullying has emerged as a relatively new form of bullying within the last decade. ${ }^{13,14}$ This new focus on cyberbullying has, in part, been driven by recent news media highlighting the connection between cyberbullying and adolescent suicides (US News, 2013 $3^{15}$ ), with one of the most recent cases involving Rebecca Sedwick, a 12-year-old girl from Polk County, FL, USA who jumped to her death after experiencing relentless acts of cyberbullying. Initial work on cyberbullying has focused on documenting prevalence rates, sex-related effects, and identifying similarities/differences to traditional forms of bullying. More recently, work has been conducted on establishing the psychosocial (for example, depression, anxiety) and psychosomatic correlates (for example, headaches, stomachaches) of cyberbullying.

Given that cyberbullying is a relatively new construct, it is important to note that there are still definitional and methodological inconsistencies throughout the literature. For example, some scholars have chosen to adopt a more conservative criterion to define cyberbullying (for example, "willful and repeated harm inflicted through the use of computers, cell phones, and other electronic devices"3,6), while other scholars have used a more broad definition (for example, "using electronic means to intentionally harm someone else" ${ }^{16}$ ). The term cyberbullying in this review will represent an umbrella term that includes related constructs such as Internet bullying, online bullying, and information communication technologies and Internet harassment. Another inconsistency in the literature includes the use of different reference points when assessing adolescents' involvement with cyberbullying. For example, some researchers have asked adolescents to think about their experiences with cyberbullying within the last year, ${ }^{17-19}$ while others have inquired about adolescents' experiences within the past 9 months, ${ }^{20}$ or the past couple of months. ${ }^{21,22}$ Given these methodological inconsistencies, it is not surprising that the prevalence rates of cyberbullying victimization and perpetration vary widely. For example, prevalence rates for cyberbullying victimization range from $4 \%-72 \%,{ }^{23,24}$ with an average of $20 \%-40 \%$ of adolescents reporting victimization via cyberbullying. ${ }^{25}$ Prevalence rates for cyberbullying perpetration also vary, ranging from $3 \%-36 \%{ }^{26,27}$ (Also unpublished data, Kowalski and Witte 2006). Although the variability is significant, the research is clear that cyberbullying is prevalent during adolescence and as such, merits further study.

The purpose of the current review is to explore the impact of cyberbullying on adolescent health across multiple studies worldwide. It is anticipated that this information can be used to increase the knowledge of practitioners, health care providers, educators, and scholars, and subsequently better inform prevention and intervention efforts related to reducing cyberbullying and its associated harm. The first section of this paper reviews the effects of cyberbullying victimization and perpetration on adolescent health. The next section includes a brief discussion of individual risk factors related to participation in cyberbullying. The third section highlights mediating and moderating processes related to the impact of cyberbullying on adolescent health. The final section addresses prevention and intervention efforts related to minimizing cyberbullying and its subsequent effect on adolescent health.

\section{Effects of cyberbullying}

The effects of cyberbullying have been predominantly explored in the area of adolescents' mental health concerns. In general, researchers have examined the relationship between involvement with cyberbullying and adolescents' tendency to internalize issues (for example, the development of negative affective disorders, loneliness, anxiety, depression, suicidal ideation, and somatic symptoms). This relationship has been explored among Finnish youth, ${ }^{28}$ Turkish youth, ${ }^{26}$ German youth, ${ }^{29}$ Asian and Pacific Islander youth, ${ }^{17}$ American youth, ${ }^{20}$ youth living in Northern Ireland, ${ }^{30}$ Swedish youth, ${ }^{31}$ Australian youth, ${ }^{32}$ Israeli youth, ${ }^{33}$ Canadian youth, ${ }^{34}$ Czech youth, ${ }^{35}$ Chinese youth, ${ }^{36}$ and Taiwanese youth. ${ }^{37}$ Although not as prolific, past work has also examined the impact of cyberbullying on adolescents' tendency to externalize issues (for example, through substance use, delinquency).

\section{Cyberbullying victimization and internalizing issues}

Past work has revealed a significant relationship between one's involvement in cyberbullying and affective disorders. For example, results indicate that there is a significant relationship between cybervictimization and depression among adolescents, ${ }^{20,38-43}$ and among college students. ${ }^{44}$ Specifically, results showed that higher levels of cyberbullying victimization were related to higher levels of depressive affect. Raskauskas and Stoltz ${ }^{45}$ asked adolescents open-ended questions about the negative effects of cyberbullying. Notably, $93 \%$ of cybervictims reported negative effects, with the majority of victims reporting feelings of sadness, hopelessness, and powerlessness. Perren et $\mathrm{al}^{39}$ further investigated the relationship between depression and cybervictimization among Swiss and Australian adolescents by controlling for traditional forms of victimization. Their results demonstrated that cybervictimization explained a significant amount of 
the variance in adolescent's depressive symptomology, even when controlling for traditional forms of victimization.

Cyberbullying has been conceptualized as a stressor. For example, Finkelhor et $\mathrm{al}^{46}$ found that $32 \%$ of targets of cyberbullying experienced at least one symptom of stress. Similarly, targets of online harassment reported increased rates of trauma symptomology. ${ }^{47}$ Relatedly, findings from the Second Youth Internet Safety Survey ${ }^{48}$ indicated that $38 \%$ of adolescent victims reported that they were emotionally distressed (ie, extremely upset) as a result of being harassed on the Internet. Not surprisingly, Sourander et $\mathrm{al}^{28}$ found that cybervictims feared for their safety. It is posited that cyberbullying is more stressful than traditional bullying, perhaps in part related to the anonymity of cyberbullying. Compared to traditional bullying, targets of cyberbullying are less likely to know their perpetrators. ${ }^{4}$ In fact, in a recent American study, half of the targets who were cyberbullied reported that they did not know their perpetrators, ${ }^{49}$ thereby contributing to increased fears related to the identities of their perpetrators. Literally, the perpetrators could be anyone; even the victims' closest friends. ${ }^{45}$ Consistent with these findings, a recent study conducted in the US found that cyberbullying victimization was related to adolescents' increased fear of victimization, even when controlling for their past victimization experiences and disordered school environments. ${ }^{50}$ Moreover, youth who were targets of cyberbullying reported increased feelings of embarrassment, hurt, self-blame, and fear. ${ }^{41,51}$ In telephone interviews with adolescents about their experiences with online harassment, Finkelhor et $\mathrm{al}^{46}$ reported that adolescents felt angry, embarrassed, and upset. Consistent with a myriad of other studies, the most common response to cyberbullying was anger, ${ }^{6,18,51,52}$ followed by upset and worry. ${ }^{52}$

However, reactions to being cyberbullied may depend on the form of cyberbullying. For example, Ortega et $\mathrm{al}^{53}$ found that different forms of cyberbullying may elicit different emotional reactions - for instance, being bullied online may evoke a different emotional reaction than being bullied via a cell phone. In terms of predicting the most deleterious outcomes, past studies have shown that pictures/video images were the most harmful to adolescents. ${ }^{9}$ In support of the need to examine unique contexts of victimization, results from a more recent study conducted in the US revealed that different forms of electronic victimization (ie, cell phones, computers) were related to different psychological outcomes, with victimization via the computer (for example, online posts, pictures, email) being more harmful to adolescents than victimization via the phone (for example, text messaging and phone calls). ${ }^{42}$
Cybervictimization is related to disruptions in adolescents' relationships. Specifically, targets of cyberbullying reported more loneliness from their parents and peers, ${ }^{54}$ along with increased feelings of isolation and helplessness. ${ }^{40}$ Not surprisingly, targets of cyberbullying reported fewer friendships, ${ }^{41}$ more emotional and peer relationship problems, ${ }^{28}$ lower school attachment, ${ }^{35,54}$ and more empathy. ${ }^{35}$ Past work has shown that adolescents who were victimized via cyberbullying were more likely to lose trust in others, ${ }^{11}$ experience increased social anxiety, ${ }^{20,42,56}$ and decreased levels of self-esteem. ${ }^{20,24,29,41-44,57,58}$ Importantly, the relationship between cybervictimization and adolescents' psychosocial problems remain even after controlling for relational and physical forms of victimization, ${ }^{20}$ as well as school-based victimization. $^{42}$

\section{Cyberbullying and suicidal behavior}

Several researchers have examined the association between involvement with cyberbullying and adolescent suicidal behavior. $^{34,38,44,55,59}$ This relationship has been explored among middle school, high school, and college students. For example, Hinduja and Patchin ${ }^{59}$ surveyed American middle school students and examined the relationship between involvement in cyberbullying (either as a victim or perpetrator) and suicidality. The results revealed that both targets and perpetrators of cyberbullying were more likely to think about suicide, as well as attempt suicide, when compared to their peers who were not involved with cyberbullying. This relationship between cyberbullying and suicidality was stronger for targets, as compared to perpetrators of cyberbullying. Specifically, targets of cyberbullying were almost twice as likely to have attempted suicide (1.9 times), whereas perpetrators were 1.5 times more likely compared to their uninvolved peers. ${ }^{59}$ Klomek et $\mathrm{al}^{38}$ looked at the relationship between cybervictimization, depression, suicidal ideation, and suicidal attempts among American high school students. Their study results showed that cyberbullying victimization was related to increased depressive affect and suicidal behavior. Similarly, using an even larger high school sample, Schneider et $\mathrm{al}^{55}$ also found a positive relationship between cybervictimization and suicidal behavior. This relationship has recently been documented among college students as well. ${ }^{44}$

In an effort to control for possible confounding variables, researchers have examined the unique contribution of cyberbullying in predicting suicidal behavior and depressive symptomology above and beyond adolescents' sex, and their involvement in relational, verbal, and physical bullying. Bonanno and $\mathrm{Hymel}^{34}$ surveyed Canadian adolescents 
and found that cybervictimization and cyberbullying contributed to adolescents' depressive symptomology and suicidal ideation over and above their sex and involvement in traditional forms of bullying (ie, face-to-face bullying). Moreover, adolescents' involvement in cyberbullying was a stronger predictor of suicidal ideation than it was for depressive symptomology. These researchers posited that perhaps, given the public and permanent nature of the computer, along with the perceived lack of control and anonymity involved, targets of cyberbullying might experience a loss of hope, thereby magnifying the relationship between cyberbullying and suicidal ideation. Those adolescents who were both victims and perpetrators of cyberbullying experienced the greatest risk for suicidal ideation. ${ }^{34}$

In sum, past work has documented the positive relationship between adolescents' involvement in cyberbullying and suicidal behavior. That is, the more adolescents are involved in cyberbullying, the more likely they are to engage in suicidal behavior; this relationship was stronger for targets than for perpetrators of cyberbullying. Recent research has expanded upon these findings and examined the potential experience(s) that might mediate the relationship between cyberbullying and suicidal behavior. ${ }^{60}$ In a recent study of American high school students, Litwiller and Brausch ${ }^{60}$ found that adolescents' substance use and violent behavior partially mediated the relationship between cyberbullying and suicidal behavior, such that increased substance use and involvement in physical violence predicted increased adolescent suicidal behavior related to cyberbullying. Further, Litwiller and Brausch ${ }^{60}$ conceptualized substance use and violent behavior as coping processes that adolescents might use to address the physical and psychological pain associated with their experiences related to cyberbullying. This study underscores the need for not only educators and health care professionals, but also parents, guardians and mentors - all caring adults to play a role in addressing adolescents' substance use and violent behavior. Results from this study suggest the need for health care providers, educators, and caring adults to equip adolescents with constructive coping strategies to effectively address cyberbullying.

\section{Cyberbullying (both victims and perpetrators) and somatic concerns}

There have been relatively few studies examining the effect of cyberbullying on adolescents' physical health. Of those studies that have been conducted, a significant relationship between cyberbullying and psychosomatic difficulties has been established. For example, Kowalski and Limber ${ }^{21}$ surveyed American adolescents and found that those youth who were both victims and perpetrators of cyberbullying experienced more severe forms of psychological (for example, anxiety, depression, and suicidal behavior) and physical health concerns (for example, problems sleeping, headache, poor appetite, and skin problems). Additionally, adolescents' grade level moderated these negative effects, with high school students who were both perpetrators and victims of cyberbullying reporting the highest levels of anxiety, depression, and the most physical health problems. Similarly, Beckman et al ${ }^{22}$ surveyed Swedish adolescents and found a positive relationship between involvement with cyberbullying and psychosomatic difficulties, including increased difficulty sleeping, stomachaches, headaches, and a lack of appetite, with adolescents who were both victims and perpetrators experiencing the most severe psychosomatic symptoms. Finally, Sourander et $\mathrm{al}^{28}$ investigated the relationship between cyberbullying and psychiatric and psychosomatic problems among Finnish adolescents. Their study results showed that cybervictims and cyberbully/ victims were more likely to experience somatic problems, including difficulty sleeping, headaches, and stomachaches, as compared to their unaffected peers. Notably, in a recent large-scale study of adolescents in Stockholm, Sweden, Låftman et $\mathrm{a}^{61}$ found that being a target of cyberbullying was associated with poorer physical health (for example, headaches, stomachaches, poor appetite, sleep disturbances, and so on), even when controlling for traditional bullying. Given that health care providers are often on the front lines responding to adolescents' somatic concerns, it is imperative that these professionals are adequately trained in the area of cyberbullying. For example, health care providers can be trained to effectively screen adolescents' for psychological and physical health issues related to cyberbulling experiences. Subsequently, it seems logical for medical schools and residency programs to consider coursework in digital networking or online social networking to increase the medical community's knowledge regarding the health correlates related to cyberbullying. ${ }^{62}$

\section{Cyberbullying victimization and externalizing issues}

Although not as well documented, the effects of cyberbullying victimization are also related to adolescents' externalizing problems. For example, among a sample of youth living in the US, Ybarra et $\mathrm{a}^{63}$ found that those adolescents who were harassed online were more likely to use alcohol, drugs, and carry a weapon at school. In fact, victimized youth were 
Table I Findings from literature on cyberbullying victimization and adolescent health using cross sectional design

\begin{tabular}{|c|c|c|c|c|}
\hline Study & Ref citation & Ages & $\mathbf{N}$ & Negative health outcomes \\
\hline Beckman et al, 2012 & 22 & $13-16$ years & 3,820 & Increased psychosomatic symptoms \\
\hline Beran and Li, 2005 & 51 & 7th-9th graders & 432 & Increased anger and sadness \\
\hline Beran and Li, 2007 & 64 & 7th-9th graders & 432 & Decreased concentration \\
\hline Bonanno and Hymel, 2013 & 34 & 8th-10th graders & 399 & Increased suicidal ideation and depression \\
\hline Campbell et al 2012 & 18 & 6th-12th graders & 3,112 & Increased anxiety, depression, and social difficulties \\
\hline Chang et al, 2013 & 37 & I0th graders & 2,992 & Decreased self-esteem and increased depression \\
\hline Dempsey et al, 2009 & 56 & $11-16$ years & 1,665 & Increased social anxiety \\
\hline Devine and Lloyd, 2012 & 30 & $10-11$ years & 3,657 & $\begin{array}{l}\text { Increased negative affect, increased loneliness, poorer } \\
\text { relationships with parents and peers }\end{array}$ \\
\hline Didden et al, 2009 & 57 & $12-19$ years & 114 & Increased depression and decreased self-esteem \\
\hline Dooley et al 2012 & 116 & $10-16$ years & 472 & $\begin{array}{l}\text { Increased depression, emotional symptoms, and conduct and } \\
\text { peer problems }\end{array}$ \\
\hline Fredstrom et al, 20II & 42 & 9th graders & 802 & $\begin{array}{l}\text { Decreased self-esteem, increased social stress, anxiousness and } \\
\text { depression, while controlling for school-based victimization }\end{array}$ \\
\hline Goebert et al, 20II & 17 & 9 th-12th graders & 677 & Increased negative feelings; increased substance use \\
\hline Hinduja and Patchin, 2007 & 72 & $6-17$ years & 1,388 & $\begin{array}{l}\text { Increased anger and frustration, increased school violence and } \\
\text { delinquency }\end{array}$ \\
\hline Hinduja and Patchin, 2008 & 13 & $\begin{array}{l}\text { Under the age of } \\
18 \text { years }\end{array}$ & $\mathrm{I}, 378$ & $\begin{array}{l}\text { Increased substance use (marijuana), school problems, and } \\
\text { delinquent behaviors }\end{array}$ \\
\hline Hinduja and Patchin, 2010 & 59 & 6th-8th graders & 1,963 & Increased suicidal thoughts and attempts \\
\hline Jackson and Cohen, 2012 & 123 & $3 r d-6$ th graders & 192 & $\begin{array}{l}\text { Increased loneliness, lower rates of peer acceptance, decreased } \\
\text { levels of optimism about peer relationships, and fewer friendships }\end{array}$ \\
\hline Juvoven and Gross, 2008 & 24 & $12-17$ years & $\mathrm{I}, 444$ & Increased social anxiety \\
\hline Katzer et al, 2009 & 29 & 5 th-1 Ith graders & 1,700 & Decreased self-concept \\
\hline Klomek et al, 2008 & 38 & $13-19$ years & 2,342 & Increased depression and suicidality \\
\hline Kowalski and Limber, 2013 & 21 & 6 th-12th graders & 931 & Decreased psychological and physical health \\
\hline Laftman et al, 2013 & 61 & $15-18$ years & 22,544 & Decreased physical health \\
\hline Litwiller and Brausch, 2013 & 60 & $14-19$ years & 4,693 & Increased suicidal behavior \\
\hline Mitchell et al, 2007 & 43 & $10-17$ years & 1,501 & Increased depression and substance use \\
\hline Olenik-Shmesh et al, 2012 & 33 & $13-16$ years & 242 & Increased loneliness and depression \\
\hline Patchin and Hinduja, 2006 & 6 & $9-17$ years & 577 & Increased frustration, anger, and sadness \\
\hline Perren et al, 2010 & 39 & 7th-10th graders & 1,694 & $\begin{array}{l}\text { Increased depression while controlling for traditional forms of } \\
\text { victimization }\end{array}$ \\
\hline Price and Dalgleish, 2010 & 41 & Under 25 years & 548 & $\begin{array}{l}\text { Increased sadness and fear; decreased friendships, self-esteem } \\
\text { and self confidence }\end{array}$ \\
\hline Randa 2013 & 50 & $12-18$ years & 3,500 & Increased fear of victimization \\
\hline Schneck and Fremouw, 2012 & 44 & 18-24 years & 799 & Increased depression, anxiety and suicidality \\
\hline Schneider et al, 2012 & 55 & 9 th-12th graders & 20,406 & Increased psychological distress \\
\hline Sourander et al, 2010 & 28 & $13-16$ years & 2,215 & Increased psychosomatic and emotional/peer problems \\
\hline Wang et al, 201 I & 40 & 6th-10th graders & 7,313 & Increased depression \\
\hline Wigderson and Lynch, 2013 & 20 & 6 th-12th graders & 388 & Increased anxiety, depression and decreased self-esteem \\
\hline Ybarra et al, 2007 & 63 & $10-15$ years & $\mathrm{I}, 588$ & $\begin{array}{l}\text { Increased alcohol and drug use; increased behavior problems and } \\
\text { weapon-carrying at school }\end{array}$ \\
\hline
\end{tabular}

eight times more likely than their peers to carry a weapon to school in the past 30 days. In a study of Asian and Pacific Islander youth, Goebert et $\mathrm{al}^{17}$ found that cyberbullying victimization was associated with adolescents' increased substance abuse. For example, targets of cyberbullying were 2.5 times more likely to use marijuana and participate in binge drinking compared to their peers. Similarly, other studies have documented a significant relationship between increased cyberbullying victimization and increased substance use. ${ }^{13,43}$ Finally, cyberbullying victimization was also related to increased levels of traditional bullying (for example, physical aggression, stealing) among a sample of adolescents living in Hong Kong. ${ }^{36}$ (See Table 1 for a summary of cross-sectional studies examining the relationship between cyberbullying victimization and negative health correlates.)

\section{Does sex matter with respect to cyberbullying victimization?}

The answer to this question is not clear. Thus far, the literature is inconsistent with respect to sex-related effects and the 
prevalence rates for cybervictimization. Some studies have found no sex differences, ${ }^{5,6,13,24,26,29,31,57,64-66}$ while other studies have found sex effects documenting higher prevalence rates for females. ${ }^{9,11,40,61}$ This sex effect indicating increased prevalence rates of cyberbullying among females has been documented among both younger and older adolescents. For example, among 10- and 11-year-olds, Devine and Lloyd ${ }^{30}$ found that girls were more likely to be victims of cyberbullying compared to boys. Kowalski and Limber ${ }^{4}$ found similar sex-based effects, documenting increased prevalence rates among adolescent females in 6 th, 7 th, and 8th grade. The same pattern has also been found among high school students. ${ }^{17}$ This sex-based effect documenting increased prevalence rates for cybervictimization among females compared to males is consistent with research showing that females are more likely to be online for social networking, while males are more likely to be online for gaming. ${ }^{68}$ Subsequently, the sheer frequency of females' online social networking behavior may provide them with more opportunities than males to become involved with cyberbullying. ${ }^{69}$

Only a few studies have documented higher prevalence rates for cyberbullying among males. For example, among German adolescents, Katzer et $\mathrm{al}^{29}$ found that males reported more victimization online than females. Among a sample of adolescents living in Cyprus, males were also at a higher risk for cybervictimization. ${ }^{70}$ Finally findings from a recent study conducted in Hong Kong indicated that males were more likely to be victimized via cyberbullying than females. ${ }^{36}$ In sum, with the exception of a handful of studies, the majority of research conducted to date has demonstrated no sex effects related to cyberbullying victimization.

\section{Cyberbullying perpetration and problem behaviors}

Generally speaking, studies that have examined the impact of cyberbullying perpetration on adolescent health have shown that those adolescent perpetrators of cyberbullying were more likely to engage in problem behaviors including higher levels of proactive and reactive aggression, property damage, ${ }^{23}$ illegal acts, ${ }^{71}$ substance use, delinquency, ${ }^{72,74}$ and suicidal behavior. ${ }^{34,59,71}$ Cyberbullying perpetration has been positively associated with hyperactivity, relational aggression, ${ }^{74}$ conduct problems, ${ }^{19,28,71}$ smoking, and drunkenness. ${ }^{22,28}$ Results from a recent study surveying Australian adolescents found that those youth who cyberbullied others reported more social difficulties, as well as more stress, depression, and anxiety compared to their peers who were not involved in any type of bullying. ${ }^{75}$ On the other hand, cyberbullying perpetration has been related to adolescents' decreased levels of self-esteem, ${ }^{76}$ selfefficacy, ${ }^{36}$ prosocial behavior, perceived sense of belonging, ${ }^{36}$ and safety at school. ${ }^{28}$ Cyberbullying perpetration has also been associated with adolescents' negative emotions such as anger, sadness, frustration, fear, and embarrassment. ${ }^{19,72,77}$ Disruptions in relationships have also been associated with cyberbullying perpetration among youth, including lower levels of empathy, ${ }^{36,74}$ increased levels of depression, ${ }^{34}$ weaker emotional bonds with caregivers, lower parental monitoring, and increased use of punitive discipline. ${ }^{73}$ Finally, perpetrators of cyberbullying were more likely to rationalize their destructive behaviors by minimizing the impact they had on others. For example, they were more likely to believe that their bullying behavior was not that harsh and that it did not bother their victims that much. ${ }^{75}$ (See Table 2 for a summary of cross-sectional studies examining the relationship between cyberbullying perpetration and negative health correlates.)

Table 2 Findings from literature on cyberbullying perpetration and adolescent health using cross sectional design

\begin{tabular}{|c|c|c|c|c|c|}
\hline Study & Country & $\begin{array}{l}\text { Reference } \\
\text { Number }\end{array}$ & Ages & $\mathbf{N}$ & Negative health correlates \\
\hline Beckman et al, 2012 & Sweden & 22 & $13-16$ years & 3,820 & Increased risk for mental health issues \\
\hline Bonanno and Hymel, 2013 & Canada & 34 & 8th-10th graders & 399 & Increased suicidal ideation and depression \\
\hline Campbell et al, 2013 & Australia & 75 & 6 th-12th graders & 3,112 & Increased stress, social difficulties, depression and anxiety \\
\hline Hinduja and Patchin, 2007 & US & 72 & 5 th-I I th graders & 1,700 & Decreased self-concept \\
\hline Hinduja and Patchin, 2010 & US & 59 & 6th-8th graders & 1,963 & Increased suicidal behavior \\
\hline Patchin and Hinduja, 2010 & US & 76 & 6th-8th graders & 1,963 & Decreased self-esteem \\
\hline Patchin and Hinduja, 20II & US & 77 & 6th-8th graders & 1,963 & Increased negative emotions \\
\hline Schneck and Fremouw, 2013 & US & 71 & 18-24 years & 856 & Increased aggression, illegal behavior and suicidality \\
\hline Sourander et al, 2010 & Finland & 28 & $13-16$ years & 2,215 & Decreased prosocial behavior and perceived safety at school \\
\hline Wong et al, 2014 & China & 36 & $12-15$ years & 1,917 & Decreased psychosocial health and sense of belonging to school \\
\hline Ybarra and Mitchell, $2004^{23}$ & US & 23 & $10-17$ years & $\mathrm{I}, 50 \mathrm{I}$ & Increased delinquent behavior, substance use \\
\hline Ybarra and Mitchell, $2004^{71}$ & US & 71 & $10-17$ years & $\mathrm{I}, 50 \mathrm{I}$ & $\begin{array}{l}\text { Poor parent-child relationships, increased substance use, and } \\
\text { delinquency }\end{array}$ \\
\hline Ybarra and Mitchell 2007 & US & 19 & $10-17$ years & $|, 50|$ & Increased aggression and rule-breaking behavior \\
\hline
\end{tabular}


Similar to cyberbullying victimization, sex-related effects for cyberbullying perpetration have also been inconsistent. For example, some studies have found an increase in female perpetration ${ }^{78}$ while other studies have indicated an increase in male cyberbullying perpetration. ${ }^{11,36,61}$ Still yet, some researchers have found no sex differences in the prevalence of cyberbullying perpetration. ${ }^{9,13,19,23}$ More research is needed before we are able to draw firm conclusions regarding the role of sex in cyberbullying perpetration.

\section{What about those adolescents who are both victims and perpetrators of cyberbullying?}

Notably, of researchers who have compared all three roles in cyberbullying, those adolescents who were both perpetrators and targets (ie, bully/victims) experienced the most adverse health outcomes, including decreased psychological and physical health. ${ }^{21,22,28,34,40}$ Specifically, these adolescents reported increased levels of depression, substance use, and conduct problems compared to their peers who were either only targets or perpetrators. ${ }^{23,21}$ Adolescents who were both targets and perpetrators of cyberbullying also reported poorer relationships with their caregivers, and higher levels of victimization and perpetration offline, compared to their peers. These results suggest that this group of adolescents (ie, bullies/victims) may experience increased risk for associated negative health outcomes, and as such, may require extra support from health care professionals, educators, and caring adults. However, we currently know relatively very little about this group of adolescents. ${ }^{79}$ More work is needed to increase our understanding of this potentially vulnerable group of adolescents.

Taken together, results from a myriad of studies worldwide suggest that involvement in cyberbullying puts adolescents at risk for increased internalizing problems including depression, anxiety, suicidal ideation, and psychosomatic concerns (for example, difficulties sleeping, headaches, and stomachaches), as well as a loss of connection from parents and peers, thereby threatening adolescents' basic fundamental need for meaningful connections. ${ }^{80}$ In addition, participation in cyberbullying also places adolescents at risk for increased externalizing issues, such as substance use and delinquent behavior.

\section{How do the developmental changes in risk factors affect subsequent cyberbullying?}

Recently, researchers have begun to examine how developmental changes in adolescent risk factors affect subsequent involvement in cyberbullying behavior. For example, Modecki et al ${ }^{81}$ recently investigated the role of increasing developmental problems (ie, problem behavior and poor emotional well-being) among adolescents (number $[\mathrm{N}]=1,364$ ) in predicting subsequent involvement in cyberbullying over a 3-year period, while controlling for sex and pubertal timing. The study findings demonstrated that adolescents' developmental increases in problem behavior across grades 8 through 10 predicted their involvement with cyberbullying in grade 11. Specifically, developmental decreases in self-esteem and increases in problem behavior (ie, substance use, aggressive behavior, and delinquency) predicted adolescents' cybervictimization and perpetration in grade 11. Interestingly, self-esteem was measured with items assessing identity and efficacy (for example, "How often do you feel satisfied with who are?" "How often do you feel sure about yourself?"). Results from this study suggest that heath care professionals and educators should carefully examine the trajectory of students' sense of self, as well as problem behaviors (for example, physical aggression and substance use) during adolescence in an effort to reduce subsequent involvement with cyberbullying. Further, these results showed that adolescents who experienced increased depression in grade 8 were at higher risk for both cybervictimization and cyberperpetration in grade 11.

Researchers have also begun to examine the risk factors that may be related to involvement with cyberbullying behavior. For example, Sticca et a $1^{67}$ examined longitudinal risk factors related to cyberbullying among 7 th grade students. Their results showed that traditional bullying and rule-breaking behavior (for example, damaging property, cigarette/alcohol use) were the strongest predictors of cyberbullying perpetration, followed by the frequency of online communication (these researchers did not look at cyberbullying victimization). In sum, these study results showed that those adolescents who bullied others in the "real world" were more than four times likely to bully someone online several months later. These results suggest that effective prevention and intervention efforts designed to reduce cyberbullying may include early detection of delinquent behaviors offline, including substance use and aggressive behavior. Moreover, results from another recent longitudinal study demonstrated that adolescents' loneliness and social anxiety predicted increases in subsequent cyberbullying victimization. ${ }^{82}$ These results suggest that adolescents who are socially vulnerable may be at increased risk for experiencing online victimization. 


\section{Potential mediating and moderating processes that may influence the effect of cyberbullying on adolescent health}

The message of past studies is clear: there is a cogent relationship between cyberbullying and negative adolescent health outcomes. In light of the negative impact of cyberbullying on adolescent health, it is imperative that future research examines potential mediating and moderating processes that might influence the impact of cyberbullying on adolescent health. We know that not all adolescents who experience cyberbullying report negative outcomes. ${ }^{6,72}$ Subsequently, individual differences among adolescents need to be considered when examining the impact of cyberbullying on adolescent health. For example, according to the transactional theory of stress and coping, ${ }^{83}$ the impact of cyberbullying does not solely depend on the event alone, but also on how the adolescent responds to the situation. We know that how adolescents respond to stressors (for example, cyberbullying) is influenced by a myriad of factors related to the individual adolescent, the context, and the stressor itself. ${ }^{83-86}$ Moreover, the language we choose also affects how adolescents respond to stressors - language can either undermine or optimize adolescents' responses. For example, the word "victim" tends to conjure up a sense of helplessness and a loss of control. ${ }^{87}$ The word "target", on the other hand, communicates deflection; that the individual has the power to deflect the aggressive behavior, thereby empowering the adolescent. ${ }^{87}$ Subsequently, it follows that an adolescent who is identified as a "victim" may be more reluctant to seek help compared to an adolescent who is identified as a "target". Clearly, the choice of language affects individuals' ensuing responses. More work is needed to increase our understanding of these and others factors that may help to protect adolescents from adverse health outcomes. Adopting a contextual framework allows researchers to identify potential protective and at-risk variables that may mediate or moderate the effects of cyberbullying on adolescents' health outcomes. Researchers and practitioners could then use this garnered knowledge to develop and sustain effective prevention and intervention programs to reduce cyberbullying behaviors and their associated harm. With that said, there is currently little known about how experiences with cyberbullying may interact with adolescents' coping strategies, sex, and social support.

\section{Coping strategies}

Schenk and Fremouw ${ }^{44}$ examined the coping strategies used by targets of cyberbullying. Their results revealed that targets of cyberbullying generally cope with cybervictimization by telling someone, avoiding friends or peers, getting revenge, and withdrawing from events, thus potentially undermining important social connections. However, Slonje and Smith ${ }^{9}$ found that $50 \%$ of targets did not tell anyone, $35.7 \%$ told a friend, $8.9 \%$ told a parent or guardian, and $5.4 \%$ told someone else. Notably, the majority of targets do not tell adults, ${ }^{10,88-91}$ with one study reporting up to $90 \%$ of adolescents not telling an adult about their experiences related to cyberbullying. ${ }^{24}$ Although these studies have begun to identify the coping strategies used by targets of cyberbullying, the majority of these studies have not examined the effectiveness of these strategies in terms of reducing or promoting subsequent at-risk behavior. Strategy effectiveness is an important construct to study, as we begin to identify those strategies that help to reduce the negative effects of cyberbullying. For example, results from a recent longitudinal study conducted in the Netherlands by Völlink et $\mathrm{al}^{93}$ demonstrated that adolescents' use of emotion-focused coping strategies negatively affected their subsequent psychological (for example, depression) and physical health (for example, chest tightness, headaches). Past work has shown that adolescents' coping strategies can mitigate or reduce the negative impact of cyberbullying, ${ }^{87}$ and as such, they should be examined further.

\section{Sex}

Future work should also continue to examine the role of sex in moderating the relationship between cyberbullying and adolescents' health. Although, as discussed earlier several studies have examined the sex effects related to the prevalence rates of cyberbullying, we know relatively very little about how sex may moderate the relationship between cyberbullying and adolescent health. In other words, is it possible that females may be more adversely affected by cyberbullying than males? This is an important question to consider when examining adolescent health outcomes. Of the few studies that have been conducted, inconsistent findings have been reported. For example, some studies have found that females are more likely to be distressed by cyberbullying than males, ${ }^{18,93,94}$ while others have reported no sex differences. ${ }^{20}$ Still yet, recent work conducted by Kowalski and Limber ${ }^{21}$ revealed that among adolescents who were both perpetrators and targets of cyberbullying, males experienced more negative psychological (for example, depression and anxiety) and physical health concerns (for example, headache, problems sleeping, and skin problems) than females. In sum, future studies are 
needed to elucidate the potential role of sex in moderating the relationship between involvement with cyberbullying and adolescent health outcomes.

\section{Social support}

Research suggests that different forms of support may mitigate the effects of traditional forms of victimization on psychological well-being. ${ }^{95-97}$ There are, however, very few studies that have examined how different forms of social support might mitigate the impact of cyberbullying on adolescent health. An exception to this is a recent study conducted by Machmutow et al, ${ }^{93}$ who examined the moderating effects of different coping strategies on the relationship between cybervictimization and depressive symptoms using a longitudinal design. Results from their study showed that adolescents' social support and feelings of helplessness predicted their depressive symptomology over time. Specifically, close feelings of social support mitigated the negative impact of cyberbullying on depressive symptomology, whereas feelings of helplessness increased depressive symptomology. Similarly, Fanti et al ${ }^{70}$ examined how different forms of social support (ie, peer, family, and school) influenced the prevalence of cyberbullying. Using a longitudinal design, Fanti et $\mathrm{al}^{70}$ found that adolescents' family social support (for example, "I get the emotional support I need from my family") was a protective factor for both cyberbullying victimization and cyberbullying perpetration, such that family social support was related to decreases in cyberbullying behaviors one year later, even after accounting for other risk factors. These results suggest that family social support may be an important protective factor in guarding against the negative health correlates of cyberbullying, and thus merits further scrutiny.

\section{Prevention and intervention}

Given the deleterious effects of cyberbullying, effective prevention and intervention efforts must be a priority. However, studies that investigate effective prevention and intervention efforts to address cyberbullying are currently lacking. ${ }^{98}$ The few studies that have addressed prevention efforts related to cyberbullying suggest that attention be directed towards enhancing adolescents' empathy and self-esteem, decreasing adolescents' problem behaviors, promoting warm, nurturing relationships with their parents, and reducing their time spent online. For example, researchers who conducted a recent study with Turkish adolescents found that those adolescents who were less empathic were more at risk for engaging in cyberbullying. Their study results demonstrated that the combined effect of affective (ie, experiencing someone else's feelings) and cognitive (ie, taking another's perspective) empathy played a vital role in influencing adolescents' participation in cyberbullying. Specifically, activating adolescents' empathy was related to less negative bystander behavior. Results from this study suggest that future prevention and intervention efforts be targeted towards increasing adolescents' affective (for example, "My friends' feelings don't affect me") and cognitive empathy (for example, "I can understand why my friend might be upset when that happens") in an effort to reduce participation in cyberbullying. ${ }^{99}$ Empathy training seems particularly important given the nature of cyberspace and the lack of nonverbal cues available. For example, adolescents may be less inclined to experience empathy for targets online in part because they are not privy to the targets' facial expressions. Subsequently, prevention efforts may need to explicitly demonstrate the hurt targets' experience in order to activate adolescents' empathic responses. ${ }^{94}$

Recent findings also suggest that prevention efforts directed towards reducing cyberbullying should address adolescents' self-esteem, as well as specific problem behaviors. Findings from a recent study revealed that developmental decreases in adolescents' self-esteem predicted their subsequent involvement in cyberbullying both as a perpetrator and as a target. ${ }^{81}$ Additionally, developmental increases in adolescents' problem behaviors (for example, substance use, delinquency, and aggressive behaviors) also predicted their involvement in cyberbullying in subsequent grades. Building on the work of Patchin and Hinduja, ${ }^{76}$ these results direct educators and health care professionals to focus on adolescents' emotional well-being during the early high school years, paying particular attention to those adolescents who experience steep declines in their self-esteem, as well as adolescents who experience steep inclines in problem behaviors including substance use and delinquency.

In terms of parental relationships, study findings suggest that health care professionals and educators should work toward helping adolescents and their parents establish warm, nurturing relationships that include close adult monitoring. This is consistent with recent suggestions by the American Academy of Pediatrics that encourage parents to participate in open discussions with children and adolescents about their online behavior, as well as to implement the necessary safeguards to protect youth from engaging in cyberbullying behaviors. ${ }^{100}$ Clearly, meaningful social connection is key to effective prevention and intervention efforts. ${ }^{101}$ Finally, results from a recent study conducted by Hinduja and Patchin ${ }^{102}$ suggest that adolescents' socializing agents (ie, friends, family, 
and adults at school) play an important role in whether or not adolescents choose to cyberbully others. Surveying a random sample of 4,441 adolescents, the study results showed that adolescents who believed that several of their friends were involved with cyberbullying were more likely to cyberbully others themselves. These results suggest the need for prevention efforts designed around correcting the "misperceived" norm of cyberbullying. Additionally, the results also indicated that adolescents who believed that the adults in their lives would hold them accountable for their involvement with cyberbullying were less likely to participate in cyberbullying, thus suggesting the important role that adults play in the lives of adolescents in terms of reducing cyberbullying behaviors.

\section{Beliefs about cyberbullying}

Adolescents' beliefs are important motivators of their behaviors. ${ }^{103}$ Past work has shown that youths' normative beliefs and attitudes about aggression are related to subsequent physical aggression, ${ }^{104,105}$ as well as relational aggression. ${ }^{106}$ More recently, research has been conducted to investigate how adolescents' beliefs about aggression influence their involvement in cyberbullying behaviors. ${ }^{107,108}$ Study results have indicated that youth who endorse attitudes supporting aggressive behaviors (for example, that it is okay to call some kids nasty names) are significantly more likely to report higher rates of cyberbullying compared to their peers. ${ }^{107,108}$ A recent study conducted among American middle school students found that students who engaged in cyberbullying were more likely to endorse supportive attitudes related to aggressive behavior. ${ }^{108}$ In addition to individual attitudes, classroom-level attitudes (although with somewhat weaker effects) were also predictive of cyberbullying behavior. ${ }^{107}$ These results at the classroom level suggest the importance of establishing and maintaining positive classroom climates, reflecting respectful treatment of all individuals. Overall, these results suggest that prevention work in the school setting is important in order to reduce cyberbullying behavior.

Finally, past studies have shown that the frequency of online communication increases the risk of cyberbullying victimization and perpetration. ${ }^{6,13,23,24,26,48,63,67,109}$ Subsequently, helping adolescents to self-regulate their time spent online may decrease their involvement with cyberbullying behaviors. This is particularly important given adolescents' struggles to manage their impulses. ${ }^{110}$

\section{Social support}

Past research has suggested that social support may be a powerful protective factor in mitigating the negative effects associated with cyberbullying. ${ }^{70,93}$ In order for adolescents to receive the necessary support they need to reduce the associated harmful effects of cyberbullying, they must be willing to seek help. However, several studies suggest that targets of cyberbullying rarely seek help from adults at school (for example, from teachers). ${ }^{19,26,111}$ Instead, the majority of adolescents are silent ${ }^{111}$ and are not likely to tell adults when they are victimized via cyberbullying. ${ }^{6,9}$ There are at least four possible reasons why adolescents are not likely to tell adults about their cyberbullying experiences. First, it could be that adolescents do not feel connected to adults, and subsequently do not seek their help when in distress. If this is true, then it is imperative that adults at school intentionally reach out to adolescents in an effort to establish trusting, caring relationships. This can be done through a variety of strategies including the development of engaging classroom activities, as well as activities designed around special adolescent interests. Prevention efforts could include helping adolescents establish and maintain meaningful social relationships with their peers. Adults at school can be trained to connect older peers with adolescents who are at risk for having fewer peer connections. A recent study conducted by Burton et $\mathrm{al}^{108}$ found that adolescents who were more attached to their peers were less likely to be involved in cyberbullying. Effective mentoring programs could be another strategy used to increase positive peer attachments among adolescents. School mentoring programs can be developed to connect adolescents to caring mentors and/or adults. Health care providers and educators can routinely screen adolescents to identify those who do not have at least one meaningful relationship with a peer and/or an adult.

Another reason that adolescents may be reluctant to tell adults about their experiences related to cyberbullying may be that youth tend to tend to think that cyberbullying is not a serious issue, and thus, they do not need help. Research has found some support for this claim. For example, Agatston et al ${ }^{112}$ found that adolescent males living in the US were less likely to view cyberbullying as a serious problem. A third reason why adolescents may not tell adults about cyberbullying may be that they do not consider the adults in their school to be helpful resources in addressing cyberbullying. ${ }^{112}$ These results suggest that additional training may be needed for school personnel to identify effective ways to address cyberbullying in the school setting. Several good resources have been provided online for educators. ${ }^{113} \mathrm{~A}$ fourth reason why adolescent targets may not be willing to seek help could be related to their increased feelings of shame and helplessness. ${ }^{40}$ Letting targeted youth know it is not their fault may be one promising cognitive strategy that may 
increase adolescents' likelihood to seek help. Recent findings from the Youth Voice Project ${ }^{114}$ suggest that adolescents' use of cognitive reframing strategies are effective tools that are likely to lead to positive outcomes for targeted youth.

Individual treatment is needed for all involved to effectively address cyberbullying. For example, adolescents can be trained to develop effective strategies to increase their self-control ${ }^{115}$ and empathy towards others. ${ }^{99}$ Recent research has also demonstrated the need for targets of cyberbullying to be trained in effective coping strategies. ${ }^{116}$ Importantly, Bauman ${ }^{117}$ suggests that counseling for the perpetrator needs to be restorative in nature and not punitive. Too often, schools tend to punish and isolate the perpetrator without any consideration for restoration with the target - a needed ingredient for optimizing adolescents' subsequent outcomes. Given the associated feelings of isolation, it is important for counselors to help targets of cyberbullying establish and maintain meaningful connections with others.

Bystanders are an important part of intervention efforts. Similar to face-to-face bullying, there are often many peers who witness or are exposed to cyberbullying. Recent findings from the Youth Voice Project compared strategy effectiveness among adolescents' self-strategies, peer strategies, and adult strategies in response to various forms of peer mistreatment. ${ }^{114}$ Results from this large-scale study showed that peer strategies (or bystander actions) were much more effective in terms of leading to positive outcomes for targeted youth than were self- or adult strategies. ${ }^{114}$ This was true for both traditional bullying and cyberbullying. Interestingly, the bystander actions that were most likely to lead to positive outcomes for targeted youth were not confrontational, but instead were quiet acts of support (ie, spent time with the targeted student, talked to them, encouraged them, listened to them, and called or messaged them at home). However, the Youth Voice Project data also revealed that over half $(51 \%)$ of the mistreated youth reported that their peers "did nothing" about the situation and "ignored what was going on". ${ }^{114}$ Clearly, more research is needed to better understand the processes underlying positive bystander behavior.

\section{What predicts positive bystander behavior?}

A recent study conducted with Czech adolescents examined whether adolescents' age, sex, self-esteem, tendency toward prosocial behavior, and problematic peer relationships influenced their support of cyberbullied peers. ${ }^{35}$ The results showed that only adolescents' tendency towards prosocial behavior positively predicted supportive bystander behavior. ${ }^{35}$ This study also examined how contextual variables might influence adolescents' bystander support of cyberbullied peers. Study findings showed that existing relationships with the target, distress experienced by witnessing the victimization, and direct appeal for help predicted positive, supportive bystander behavior. On the other hand, having a strong relationship with the perpetrator repressed supportive bystander behavior. These results are consistent with past work documenting the importance of empathy, as well as the importance of training adolescents to ask for help from their peers. Importantly, these results also underscore the significance of developing and maintaining prosocial relationships among adolescents. Recent researchers in Belgium used an experimental paradigm to investigate the effect of contextual variables on bystander actions in response to a hypothetical cyberbullying incident. ${ }^{118}$ Their study results showed that among Flemish adolescents, bystanders were more likely to help the target when they perceived the cyberbullying to be more severe, which suggests that we need to help adolescents understand the seriousness of cyberbullying.

\section{What predicts negative bystander behavior?}

In a recent study conducted in Poland, researchers used an experimental paradigm to examine the individual factors that might influence adolescents' negative bystander behavior in response to cyberbullying. ${ }^{119}$ The results indicated that negative bystander behavior (as measured by the decision to forward a negative message about someone) was more likely to occur in private contexts, as compared to public contexts. For example, adolescents were likely to behave in more antisocial ways when they thought only one or a few observers would see their behavior (ie, private conditions). These findings suggest that it is important for adolescents to understand that in reality, their online behavior is seen by a wide audience and is, in fact, "public". The results also showed that negative bystander behavior was more likely among adolescents who had previous experiences with cyberbullying perpetration. Finally, consistent with past work, study findings demonstrated that both affective and cognitive empathy reduces negative bystander behavior. Overall, the results suggest that educators, health care professionals, and caring adults should continue to promote adolescents' prosocial relationships, affective and cognitive empathy, as well as help adolescents to seek out positive forms of social support. Although initial research has begun to examine the effect of bystanders in the context of cyberbullying, more work is needed to understand how bystander actions may influence the relationship between cyberbullying and associated health outcomes. Another recent study using an 
experimental paradigm to examine individual factors related to negative bystander behavior was conducted in Belguim. ${ }^{118}$ Results from this study indicated that bystanders were more likely to "join in" on the bullying when the other bystanders were good friends as opposed to acquaintances. Consistent with past work, ${ }^{114}$ sex-related effects were found, such that females were more likely to comfort and defend the target, give advice to the target, and report the incident. On the other hand, males were more likely to reinforce the cyberbullying by telling the perpetrator that they thought it was funny. ${ }^{118}$ These sex-related effects indicate that adolescent males may require extra training related to providing positive support to peers who have been victimized via cyberbullying.

In sum, raising awareness among educators, health care professionals, parents, and adolescents regarding the serious nature of cyberbullying may be a first step in addressing the harmful effects of cyberbullying. Moreover, it is important for caring adults and mentors to proactively reach out to adolescents and establish meaningful relationships with them that persist over time. Additionally, training adults and adolescents in effective strategies to address cyberbullying is needed to mitigate the associated negative effects of cyberbullying. Finally, addressing adolescents' beliefs around cyberbullying both at the individual and classroom level should be at the core of prevention and intervention efforts. ${ }^{108}$ School counselors and health care providers may be in a prime position to initiate training for school personnel, parents, and adolescents alike. ${ }^{120}$

\section{When should prevention and intervention efforts begin?}

It is important for researchers to begin looking at how younger children interface with technology. Cyberbullying prevention and intervention programs should target all grade levels. ${ }^{121}$ The research is clear that cyberbullying begins before adolescence. ${ }^{122}$ To date, however, the majority of studies investigating cyberbullying have primarily included teenagers (Table 1 and Table 2). Although teenagers are an important population to study given their salient developmental concerns, ${ }^{110}$ more work is needed to examine how younger adolescents (for example, 9-11-year-olds) are affected by cyberbullying experiences. Englander, from the MA Aggression Reduction Center (MARC; http://marccenter.webs.com/), has begun to study the prevalence of technology among younger children. Her work has shown that over $90 \%$ of children are already immersed online by the time they are 8 years old. This has implications for involvement in subsequent cyberbullying. For example, research has demonstrated that owning a "Smartphone" in elementary school increases a child's risk for being involved with cyberbullying both as the target, as well as the perpetrator. ${ }^{122}$ Devine and Lloyd ${ }^{30}$ examined Internet use and psychological well-being among 10- and 11-year-old children living in Northern Ireland. Their results showed a moderate, significant relationship between cybervictimization and psychological well-being. Specifically, children who experienced more victimization online were likely to experience more negative affect, more loneliness, and poorer relationships with their parents and peers. Similarly, Jackson and Cohen ${ }^{122}$ found a positive relationship between loneliness and cyberbullying victimization among 3rd through 6 th graders. Further, cyberbullying victimization was related to fewer friendships, lower rates of optimism in describing peer relationships, and lower peer acceptance. Additional work is needed with this younger age group to help increase our understanding of the impact of cyberbullying on adolescent health.

\section{Conclusion}

In sum, research has demonstrated that cyberbullying victimization and perpetration have a significant detrimental impact on adolescents' health (Table 1 and Table 2). In fact, the studies reviewed herein suggest that cyberbullying is an emerging international public health concern, related to serious mental health concerns, with significant impact on adolescents' depression, anxiety, self-esteem, emotional distress, substance use, and suicidal behavior. Moreover, cyberbullying is also related to adolescents' physical health concerns.

It is important to note that the majority of studies investigating the relationship between cyberbullying behaviors and adolescent health have been correlational in nature. While correlational studies are an important first step to understanding the impact of cyberbullying, longitudinal studies are now needed to increase our understanding of how cyberbullying experiences affect adolescents' health over time. By using longitudinal designs, we are able to test whether adolescents' depressive symptoms, social anxiety, or suicidal tendencies related to cyberbullying are antecedents or consequences. For example, it is possible that depressive symptomology could either be an antecedent or an effect of cyberbullying victimization. Longitudinal study designs permit us to examine both of these possibilities with more clarity. As discussed in the section titled, "How do the developmental changes in risk factors affect subsequent cyberbullying?", an emerging body of work has begun to use longitudinal designs to examine the risk factors related to increased involvement 
with cyberbullying perpetration and victimization over time. However, more longitudinal work is needed to increase our understanding of the temporal nature of variables related to cyberbullying experiences.

Findings from the current literature have significant implications for health care professionals, educators, and caring adults. First and foremost, the studies described throughout urge educators, counselors, and health care professionals to address cyberbullying when assessing adolescents' physical and psychological health concerns. It is clear that adolescents who are involved in cyberbullying experiences require support. However, evidence suggests that the majority of adolescents do not seek help from adults when involved in cyberbullying. Therefore, it is important to take a proactive approach. Support could come from multiple professional communities that serve youth: educational (for example, professionals working in the schools); behavioral health (for example, clinicians treating adolescents with mental health concerns); and medical (for example, pediatricians asking about cyberbullying experiences during sick and well visits). Sensitive probing about cyberbullying experiences is warranted when addressing adolescent health issues such as depression, substance use, suicidal ideation, as well as somatic concerns. Routine screening techniques can be developed to assist in uncovering the harm endured through cyberbullying to help support adolescents recovering from associated trauma. Finally, the study findings described above also suggest a strong need for comprehensive, schoolbased programs directed at cyberbullying prevention and intervention. Education about cyberbullying could be integrated into school curriculums and the community at large, for example, by engaging adolescents in scholarly debates and community discussions related to cyberbullying legislation, accountability, and character.

\section{Disclosure}

The author reports no conflicts of interest in this work.

\section{References}

1. Englander EK. Spinning our wheels: improving our ability to respond to bullying and cyberbullying. Child Adolesc Psychiatr Clin N Am. 2012;21(1):43-55, viii.

2. Lenhart A, Madden M, Smith A, Purcell K, Zickuhr K, Rainie L [webpage on the Internet]. Teens, kindness and cruelty on social network sites. 2011. Available from: http://pewinternet.org/Reports/2011/Teensand-social-media/Summary/Findings.aspx. Accessed March 7, 2014.

3. Hinduja S, Patchin JW. Bullying Beyond the Schoolyard: Preventing and Responding to Cyberbullying. Thousand Oaks, CA: Sage; 2009.

4. Kowalski RM, Limber SP. Electronic bullying among middle school students. J Adolesc Health. 2007;41(6 Suppl 1):S22-S30.
5. Li Q. New bottle but old wine: a research of cyberbullying in schools Comput Human Behav. 2007;23(4):1777-1791.

6. Patchin JW, Hinduja S. Bullies move beyond the schoolyard: a preliminary look at cyberbullying. Youth Violence Juv Justice. 2006;4(2):148-169.

7. Willard NE, Steiner K. Cyberbullying and Cyberthreats: Responding to the Challenge of Online Social Aggression, Threats, and Distress. Champaign, IL: Research Press; 2007.

8. Baker CK, Helm S. Pacific youth and shifting thresholds: understanding teen dating violence in Hawai'i. $J$ Sch Violence. 2010;9(2):154-173.

9. Slonje R, Smith PK. Cyberbullying: another main type of bullying? Scand J Psychol. 2008;49(2):147-154.

10. Campbell MA. Cyber bullying: an old problem in a new guise? Australian Journal of Guidance and Counselling. 2005;15(1):68-76.

11. Dehue F, Bolman C, Völlink T. Cyberbullying: youngsters' experiences and parental perception. Cyberpsychol Behav. 2008;11(2):217-223.

12. Suler J. The online disinhibition effect. Cyberpsychol Behav. 2004; 7(3):321-326.

13. Hinduja S, Patchin JW. Cyberbullying: an exploratory analysis of factors related to offending and victimization. Deviant Behav. 2008;29(2):129-156.

14. Kowalski RM, Limber SP, Agatston PW. Cyberbullying: Bullying in the Digital Age. 2nd ed. Malden, MA: Wiley-Blackwell; 2012.

15. USA Today [webpage on the Internet]. Two girls arrested on bullying charges after suicide. McLean, VA: USATODAY; 2013. Available from: http://www.usatoday.com/story/news/nation/2013/10/15/ florida-bullying-arrest-lakeland-suicide/2986079/. Accessed April 4, 2014.

16. Smith PK, del Barrio C, Tokunaga R. Definitions of cyberbullying: how useful are the terms? In: Bauman S, Cross D, Walker J, editors. Principles of Cyberbullying Research: Definitions, Measures, and Methodology. New York, NY: Routledge; 2013:26-45.

17. Goebert D, Else I, Matsu C, Chung-Do J, Chang JY. The impact of cyberbullying on substance use and mental health in a multiethnic sample. Matern Child Health J. 2011;15(8):1282-1286.

18. Campbell MA, Spears B, Slee P, Butler DA, Kift SM. Victims' perceptions of traditional and cyberbullying, and the psychosocial correlates of their victimisation. Emotional and Behavioural Difficulties. 2012;17(3-4):389-401.

19. Ybarra ML, Mitchell KJ. Prevalence and frequency of Internet harassment instigation: implications for adolescent health. J Adolesc Health. 2007;41(2):189-195.

20. Wigderson S, Lynch M. Cyber- and traditional peer victimization: unique relationships with adolescent well-being. Psychol Violence. 2013;3(4):297-309.

21. Kowalski RM, Limber SP. Psychological, physical, and academic correlates of cyberbullying and traditional bullying. JAdolesc Health. 2013;53(Suppl 1):S13-S20.

22. Beckman L, Hagquist C, Hellström L. Does the association with psychosomatic health problems differ between cyberbullying and traditional bullying? Emotional and Behavioural Difficulties. 2012;17(3-4):421-434.

23. Ybarra ML, Mitchell KJ. Online aggressor/targets, aggressors, and targets: a comparison of associated youth characteristics. $J$ Child Psychol Psychiatry. 2004;45(7):1308-1316.

24. Juvonen J, Gross EF. Extending the school grounds? - Bullying experiences in cyberspace. $J$ Sch Health. 2008;78(9):496-505.

25. Tokunaga RS. Following you home from school: a critical review and synthesis of research on cyberbullying victimization. Comput Human Behav. 2010;26(3):277-287.

26. Aricak T, Siyahhan S, Uzunhasanoglu A, et al. Cyberbullying among Turkish adolescents. Cyberpsychol Behav. 2008;11(3):253-261.

27. WiredSafety.org [homepage on the Internet]. Wired Safety. 2012. Available from: https://www.wiredsafety.org. Accessed March 30, 2014.

28. Sourander A, Brunstein Komek A, Ikonen M, et al. Psychosocial risk factors associated with cyberbullying among adolescents: a populationbased study. Arch Gen Psychiatry. 2010;67(7):720-728. 
29. Katzer C, Fetchenhauer D, Belschak F. Cyberbullying: who are the victims? A comparison of victimization in internet chatrooms and victimization in school. Journal of Media Psychology: Theories, Methods, and Applications. 2009;21(1):25-36.

30. Devine P, Lloyd K. Internet use and psychological well-being among 10-year-old and 11-year-old children. Child Care in Practice. 2012;18(1):5-22.

31. Slonje R, Smith PK, Frisén A. Processes of cyberbullying, and feelings of remorse by bullies: a pilot study. Eur J Dev Psychol. 2012;9(2): 244-259.

32. Hemphill SA, Kotevski A, Tollit M, et al. Longitudinal predictors of cyber and traditional bullying perpetration in Australian secondary school students. J Adolesc Health. 2012;51(1):59-65.

33. Olenik-Shemesh D, Heiman T, Eden S. Cyberbullying victimisation in adolescence: relationships with loneliness and depressive mood. Emotional and Behavioural Difficulties. 2012;17(3-4):361-374.

34. Bonanno RA, Hymel S. Cyber bullying and internalizing difficulties: above and beyond the impact of traditional forms of bullying. $J$ Youth Adolesc. 2013;42(5):685-697.

35. Macháčková H, Dedkova L, Sevcikova A, Cerna A. Bystanders' support of cyberbullied schoolmates. J Community Appl Soc Psychol. 2013; 23(1):25-36.

36. Wong DSW, Chan HCO, Cheng CHK. Cyberbullying perpetration and victimization among adolescents in Hong Kong. Child Youth Serv Rev. 2014;36:133-140

37. Chang FC, Lee CM, Chiu CH, Hsi WY, Huang TF, Pan YC. Relationships among cyberbullying, school bullying, and mental health in Taiwanese adolescents. J Sch Health. 2013;83(6):454-462.

38. Klomek AB, Marrocco F, Kleinman M, Schonfeld IS, Gould MS. Peer victimization, depression, and suicidiality in adolescents. Suicide Life Threat Behav. 2008;38(2):166-180.

39. Perren S, Dooley J, Shaw T, Cross D. Bullying in school and cyberspace: associations with depressive symptoms in Swiss and Australian adolescents. Child Adolesc Psychiatry Ment Health. 2010;4:28

40. Wang J, Nansel TR, Iannotti RJ. Cyber and traditional bullying: differential association with depression. J Adolesc Health. 2011;48(4):415-417.

41. Price M, Dalgleish J. Cyberbullying experiences, impacts and coping strategies as described by Australian young people. Youth Studies Australia. 2010;29(2):51.

42. Fredstrom BK, Adams RE, Gilman R. Electronic and school-based victimization: unique contexts for adjustment difficulties during adolescence. J Youth Adolesc. 2011;40(4):405-415.

43. Mitchell KJ, Ybarra M, Finkelhor D. The relative importance of online victimization in understanding depression, delinquency, and substance use. Child Maltreat. 2007;12(4):314-324.

44. Schenk AM, Fremouw WJ. Prevalence, psychological impact, and coping of cyberbully victims among college students. J Sch Violence. 2012;11(1):21-37.

45. Raskauskas J, Stoltz AD. Involvement in traditional and electronic bullying among adolescents. Dev Psychol. 2007;43(3):564-575.

46. Finkelhor D, Mitchell KJ, Wolak J. Online Victimization: A Report on the Nation's Youth. Washington, DC: National Center for Missing and Exploited Children; 2000.

47. Mitchell KJ, Jones LM, Finkelhor D, et al. Youth Internet Safety Survey. Durham, NH: Crimes Against Children Research Center, University of New Hampshire; 2011.

48. Ybarra ML, Mitchell KJ, Wolak J, Finkelhor D. Examining characteristics and associated distress related to Internet harassment: findings from the Second Youth Internet Safety Survey. Pediatrics. 2006;118(4): e1169-e1177.

49. Bauman S. Cyberbullying in a rural intermediate school: an exploratory study. J Early Adolesc. 2010;30(6):803-833.

50. Randa R. The influence of the cyber-social environment on fear of victimization: cyberbullying and school. Security Journal. 2013;26(4): 331-348.
51. Beran T, Li Q. Cyber-harassment: a study of a new method for an old behavior. Journal of Educational Computing Research. 2005;32(3): 265-277.

52. Ortega R, Elipe P, Mora-Merchán JA, et al. The emotional impact of bullying and cyberbullying on victims: a European cross-national study. Aggress Behav. 2012;38(5):342-356.

53. Ortega R, Elipe P, Mora-Merchán JA, Calmaestra J, Vega E. The emotional impact on victims of traditional bullying and cyberbullying: a study of Spanish adolescents. Z Psychol. 2009;217(4):197-204.

54. Brighi A, Melotti G, Guarini A, et al. Self-esteem and loneliness in relation to cyberbullying in three European countries. In: Li Q, Cross D, Smith PK, editors. Cyberbullying in the Global Playground: Research from International Perspectives. Chichester, UK: John Wiley and Sons; 2012:32-56

55. Schneider SK, O'Donnell L, Stueve A, Coulter RW. Cyberbullying, school bullying, and psychological distress: a regional census of high school students. Am J Public Health. 2012;102(1):171-177.

56. Dempsey AG, Sulkowski ML, Nichols R, Storch EA. Differences between peer victimization in cyber and physical settings and associated psychosocial adjustment in early adolescence. Psychol Sch. 2009; 46(10):962-972.

57. Didden R, Scholte RH, Korzilius H, et al. Cyberbullying among students with intellectual and developmental disability in special education settings. Dev Neurorehabil. 2009;12(3):146-151.

58. Ybarra ML. Linkages between depressive symptomatology and Internet harassment among young regular Internet users. Cyberpsychol Behav. 2004;7(2):247-257.

59. Hinduja S, Patchin JW. Bullying, cyberbullying, and suicide. Arch Suicide Res. 2010;14(3):206-221.

60. Litwiller BJ, Brausch AM. Cyber bullying and physical bullying in adolescent suicide: the role of violent behavior and substance use. J Youth Adolesc. 2013;42(5):675-684.

61. Låftman SB, Modin B, Östberg V. Cyberbullying and subjective health: a large-scale study of students in Stockholm, Sweden. Child Youth Serv Rev. 2013;35(1):112-119.

62. Sivashanker K. Cyberbullying and the digital self. J Am Acad Child Adolesc Psychiatry. 2013;52(2):113-115.

63. Ybarra ML, Diener-West M, Leaf PJ. Examining the overlap in Internet harassment and school bullying: implications for school intervention. J Adolesc Health. 2007;41(6 Suppl 1):S42-S50.

64. Beran T, Li Q. The relationship between cyberbullying and school bullying. The Journal of Student Wellbeing. 2007;1(2):15-33.

65. Varjas K, Henrich CC, Meyers J. Urban middle school students' perceptions of bullying, cyberbullying, and school safety. J Sch Violence. 2009;8(2):159-176.

66. Williams KR, Guerra NG. Prevalence and predictors of Internet bullying. J Adolesc Health. 2007;41(6 Suppl 1):S14-S21.

67. Dowell EB, Burgess AW, Cavanaugh DJ. Clustering of Internet risk behaviors in a middle school student population. J Sch Health. 2009;79(11):547-553.

68. Sticca F, Ruggieri S, Alsaker F, Perren S. Longitudinal risk factors for cyberbullying in adolescence. Journal of Community and Applied Social Psychology. 2013;23(1):52-67.

69. Snell PA, Englander EK. Cyberbullying victimization and behaviors among girls: applying research findings in the field. Journal of Social Sciences. 2010;6(4):510-514.

70. Fanti KA, Demetriou AG, Hawa VV. A longitudinal study of cyberbullying: examining risk and protective factors. EurJ Dev Psychol. 2012;9(2):168-181.

71. Schenk AM, Fremouw WJ, Keelan CM. Characteristics of college cyberbullies. Comput Human Behav. 2013;29(6):2320-2327.

72. Hinduja S, Patchin JW. Offline consequences of online victimization: school violence and delinquency. J Sch Violence. 2007; 6(3):89-112.

73. Ybarra ML, Mitchell KJ. Youth engaging in online harassment: associations with caregiver-child relationships, Internet use, and personal characteristics. J Adolesc. 2004;27(3):319-336. 
74. Schultze-Krumbholz A, Scheithauer H. Social-behavioral correlates of cyberbullying in a German student sample. Z Psychol. 2009;217(4): 224-226.

75. Campbell MA, Slee PT, Spears B, Butler D, Kift S. Do cyberbullies suffer too? Cyberbullies' perceptions of the harm they cause to others and to their own mental health. Sch Psychol Int. 2013;34(6): 613-629.

76. Patchin JW, Hinduja S. Cyberbullying and self-esteem. J Sch Health. 2010;80(12):614-621; quiz 622.

77. Patchin JW, Hinduja S. Traditional and nontraditional bullying among youth: a test of general strain theory. Youth and Society. 2011;43(2):727-751.

78. Jones LM, Mitchell KJ, Finkelhor D. Trends in youth Internet victimization: findings from three youth Internet safety surveys 2000-2010. J Adolesc Health. 2012;50(2):179-186.

79. Mishna F, Khoury-Kassabri M, Gadalla T, Daciuk J. Risk factors for involvement in cyber bullying: victims, bullies and bully-victims. Child Youth Serv Rev. 2012;34(1):63-70.

80. Baumeister RF, Leary MR. The need to belong: desire for interpersonal attachments as a fundamental human motivation. Psychol Bull. 1995;117(3):497-529.

81. Modecki KL, Barber BL, Vernon L, Vernon L. Mapping developmental precursors of cyber-aggression: trajectories of risk predict perpetration and victimization. J Youth Adolesc. 2013;42(5):651-661.

82. van den Eijnden R, Vermulst A, van Rooij AJ, Scholte R, van de Mheen D. The bidirectional relationships between online victimization and psychosocial problems in adolescents: a comparison with real-life victimization. J Youth Adolesc. 2014;43(5):790-802.

83. Lazarus RS, Folkman S. Stress, Appraisal, and Coping. New York, NY: Springer-Verlag; 1984

84. Compas BE, Connor-Smith JK, Saltzman H, Thomsen AH, Wadsworth ME. Coping with stress during childhood and adolescence: problems, progress, and potential in theory and research. Psychol Bull. 2001;127(1):87-127.

85. Griffith MA, Dubow EF, Ippolito MF. Developmental and crosssituational differences in adolescents' coping strategies. JYouth Adolesc. 2000;29(2):183-204.

86. Lazarus RS. Stress and Emotion: A New Synthesis. New York, NY: Springer; 1999.

87. Fried S. Beyond bullying: transforming the culture of peer abuse. Journal of Applied Research on Children: Informing Policy for Children at Risk. 2013;10(4):1-17.

88. Agatston P, Kowalski R, Limber S. Youth views on cyberbullying. In: Patchin JW, Hinduja S, editors. Cyberbullying Prevention and Response: Expert Perspectives. New York, NY: Routledge; 2012: 55-71.

89. Cassidy W, Jackson M, Brown KN. Sticks and stones can break my bones, but how can pixels hurt me? Students' experiences with cyber-bullying. School Psychol Int. 2009;30(4):383-402.

90. Dooley JJ, Gradinger P, Strohmeier D, Cross D, Spiel C. Cybervictimisation: the association between help-seeking behaviours and self-reported emotional symptoms in Australia and Austria. Australian Journal of Guidance and Counselling. 2010;20(2):194-209.

91. Yilmaz H. Cyberbullying in Turkish middle schools: an exploratory study. School Psychol Int. 2011;32:645-654.

92. Völlink T, Bolman CAW, Dehue F, Jacobs NCL. Coping with cyberbullying: differences between victims, bully-victims and children not involved in bullying. J Community Appl Soc Psychol. 2013;23(1): 7-24.

93. Machmutow K, Perren S, Sticca F, Alsaker FD. Peer victimization and depressive symptoms: can specific coping strategies buffer the negative impact of cybervictimisation? Emotional and Behavioural Difficulties. 2012;17(3-4):403-420.

94. Bauman S, Newman ML. Testing assumptions about cyberbullying: perceived distress associated with acts of conventional and cyber bullying. Psychol Violence. 2013;3(1):27-38.

95. Davidson LM, Kilpatrick Demaray M. Social support as a moderator between victimization and internalizing-externalizing distress from bullying. Social Psychology Review. 2007;36(3):383-405.
96. Holt MK, Espelage DL. Perceived social support among bullies, victims, and bully-victims. J Youth Adolescence. 2007;36: 984-994.

97. Kochenderfer-Ladd B, Skinner K. Children's coping strategies: moderators of the effects of peer victimization? Dev Psychol. 2002; 38(2):267-278.

98. von Marées N. Cyberbullying: an increasing challenge for schools. Sch Psychol Int. 2012;33(5):467-476.

99. Topcu Ç, Erdur-Baker Ö. Affective and cognitive empathy as mediators of gender differences in cyber and traditional bullying. Sch Psychol Int. 2012;33(5):550-561.

100. Schurgin O'Keeffe G, Clarke-Pearson K; Council on Communications and Media. Clinical report - the impact of social media on children, adolescents, and families. Pediatrics. 2011;127:800-804.

101. Davis S, Nixon Cl. Empowering bystanders. In: Patchin J, Hinduja S, editors. Cyberbullying Prevention and Response: Expert Perspectives. New York, NY: Routledge; 2012:93-113.

102. Hinduja S, Patchin JW. Social influences on cyberbullying behaviors among middle and high school students. J Youth Adolesc. 2013;42(5): 711-722.

103. Bandura A. Social Foundations of Thought and Action: A Social Cognitive Theory. Englewood Cliffs, NJ: Prentice-Hall; 1986.

104. Huesmann LR, Guerra NG. Children's normative beliefs about aggression and aggressive behavior. J Pers Soc Psychol. 1997;72(2): 408-419.

105. van Goethem AA, Scholte RH, Wiers RW. Explicit- and implicit bullying attitudes in relation to bullying behavior. J Abnorm Child Psychol. 2010;38(6):829-842.

106. Werner NE, Nixon CL. Normative beliefs and relational aggression: an investigation of the cognitive bases of adolescent aggressive behavior. $J$ Youth Adolesc. 2005;34(3):229-243.

107. Christian Elledge L, Williford A, Boulton AJ, Depaolis KJ, Little TD, Salmivalli C. Individual and contextual predictors of cyberbullying: the influence of children's provictim attitudes and teachers' ability to intervene. J Youth Adolesc. 2013;42(5):698-710.

108. Burton KA, Florell D, Wygant DB. The role of peer attachment and normative beliefs about aggression on traditional bullying and cyberbullying. Psychol Sch. 2013;50(2):103-115.

109. Li Q. A cross-sectional comparison of adolescents' experience related to cyberbullying. Educ Res. 2008;50(3):223-234.

110. Steinberg L. A social neuroscience perspective on adolescent risktaking. Dev Rev. 2008;28(1):78-106.

111. Smith PK, Mahdavi J, Carvalho M, Fisher S, Russell S, Tippett N. Cyberbullying: its nature and impact in secondary school pupils J Child Psychol Psychiatry. 2008;49(4):376-385.

112. Agatston PW, Kowalksi R, Limber S. Students' perspectives on cyber bullying. J Adolesc Health. 2007;41(6 Suppl 1):S59-S60.

113. Willard N. An Educator's Guide to Cyberbullying and Cyberthreats: Responding to the Challenges of Online Social Aggression, Threats, and Distress. Center for Safe and Responsible Use of the Internet; 2005.

114. Davis S, Nixon CL. Youth Voice Project: Student Insights into Bullying and Peer Mistreatment. Champaign, IL: Research Press Publishers; 2013.

115. Vazsonyi AT, Machackova H, Sevcikova A, Smahel D, Cerna A. Cyberbullying in context: direct and indirect effects by low selfcontrol across 25 European countries. Eur J Dev Psychol. 2012;9(2): 210-227.

116. Dooley JJ, Shaw T, Cross D. The association between the mental health and behavioural problems of students and their reactions to cyber-victimization. Eur J Dev Psychol. 2012;9(2):275-289.

117. Bauman S. Cyberbullying: What Counselors Need to Know. Alexandria, VA: American Counseling Association; 2010.

118. Bastiaensens S, Vandebosch H, Poels K, Van Cleemput K, DeSmet A, De Bourdeaudhuij I. Cyberbullying on social network sites. An experimental study into bystanders' behavioural intentions to help the victim or reinforce the bully. Comput Human Behav. 2014;31:259-271. 
119. Barlińska J, Szuster A, Winiewski M. Cyberbullying among adolescent bystanders: role of the communication medium, form of violence, and empathy. J Community Appl Soc Psychol. 2013;23(1):37-51.

120. Bhat CS. Cyber bullying: overview and strategies for school counselors, guidance officers, and all school personnel. Australian Journal of Guidance and Counselling. 2008;18(1):53-66.

121. Limber SP, Kowalksi RM, Agatston PW. Cyber Bullying: A Prevention Curriculum for Grades 6-12. Center City, MN: Hazelden Information and Educational Services; 2009.
122. Englander EK. Bullying and Cyberbullying: What Every Educator Needs to Know. Cambridge, MA: Harvard Educational Press; 2013.

123. Jackson CL, Cohen R. Childhood victimization: modeling the relation between classroom victimization, cyber victimization, and psychosocial functioning. Psychol Pop Media Cult. 2012;1(4): 254-269.

\section{Publish your work in this journal}

Adolescent Health, Medicine and Therapeutics is an international, peer-reviewed, open access journal focusing on health, pathology, and treatment issues specific to the adolescent age group. All aspects of health maintenance, preventative measures and disease treatment interventions are addressed within the journal and practitioners from all disciplines are invited to submit their work as well as healthcare researchers and patient support groups.. The manuscript management system is completely online and includes a very quick and fair peerreview system. Visit http://www.dovepress.com/testimonials.php to read real quotes from published authors.

Submit your manuscript here: http://www.dovepress.com/adolescent-health-medicine-and-therapeutics-journal 